\title{
Understanding the Role of Tacit Knowledge in Call-Center Organizations
}

\author{
Samantha Okegbe ${ }^{1}$ \\ ${ }^{1}$ Department of Communication, The University of Illinois Urbana-Champaign, Illinois.
}

Author email: sokegbe2@illinois.edu

Author full postal address: 6805 Townbrook Dr. Apt D, Gwynn Oak, Maryland, 21207. 


\title{
Understanding the Role of Tacit Knowledge in Call-Center Organizations
}

\begin{abstract}
This article aims to understand the role of tacit knowledge in call center organizations with the objective of understanding how call center representatives use tacit knowledge in their job roles and functions. Extant literature has focused on explicit knowledge but the research on tacit knowledge is still underdeveloped. The complexities and difficulties of the call center job role and the usage and transfer of knowledge is reviewed. Also, it takes into considerations past literature on tacit knowledge, how these respondents employ tacit knowledge in efficiently handling customers, responding to their queries, and engaging this form of knowledge in problem solving. The article concludes with discussion and implications for call center organizations and responders.
\end{abstract}

Key words: Tacit knowledge, organizational communication, call-center, responders

\section{Introduction}

Extant literature and organizations have emphasized the importance of training workers based on explicit knowledge with little or no attention in using their awareness in responding to customers issues especially in emergency call center organizations. However, this paper attempts to explore the role of tacit knowledge and how it can be applied to industries that regularly attend to customers queries and problems. This paper explores and reviews the importance of this form of communication in customer care jobs and its use in enhancing customer satisfaction. Despite this form of knowledge lacking the ability to be codified, organizations can train industry works to pay 
careful attention and employ knowledge beyond what has been codified in manuals for them. One of the ways this can be done is through the art of storytelling in organizations.

This paper takes the following structure: a brief overview on what is knowledge and organizational knowledge. The next section examines and reviews literature on the roles of tacit knowledge in practice. The study explores the use of tacit knowledge in call center organizations and why this form of communication is difficult. Throughout the paper, an argument is made of how these workers use knowledge tacitly, its influence on their actions, and communicative practices. Finally, the paper concludes with the discussion and implications for organizations in this field.

\section{Knowledge}

There has been different proponents on the perspective of what is knowledge. Some consider knowledge as residing within an individual, others within the organization, and some relate it to human action (Tsoukas \& Vladimirou, 2001). Another term that has been widely debated about is the use of data, information and knowledge being used interchangeably. Davenport and Prusak (1998) argue that these terms are not concepts that are interchangeable, and the success or failure of an organization depends on knowing if you have data, information or knowledge in the organization, and knowing when and how to use any of them. However, this paper does not dwell on the debate of the conceptualization of knowledge or if information, data and knowledge are terms that can be used interchangeably or not.

The term knowledge is used in this paper by adopting Davenport and Prusak (1998, p. 5) definition of knowledge, "a flux mix of framed experiences, values, contextual information, and expert insight that provides a framework for evaluating and incorporating new experiences and information". They add that in organizations, this knowledge is often embedded in routines, 
processes, practices, and norms. I argue that knowledge in call center is embedded deeply in their routines, processes, practice and norms, as opposed to only in their explicit standardized manuals or rulebooks. On the other hand, organization is considered a network of communication that is densely connected in which shared understanding are accomplished (Tsoukas \& Vladimirou, 2001). Call centers are organizations that are densely connected especially through their different departments and service agents and it is a place in which shared understanding is crucial for the daily operations of the centers. This shared understanding occurs within the networks of agents and between the operators and the customers who call in.

\section{Tacit Knowledge}

Polanyi (1962) argues that "there are things that we know but we cannot tell" (p. 609). He uses an example of riding a bike to describe how you can tell someone you know how to ride a bike or teach them how to ride it, but you cannot tell them how to keep their balance. I argue that this occurs in $\mathrm{CCO}$ where call center representatives resolve some customers problems by thinking on their feet or thinking of a solution that is off the books or manuals. But cannot explain how they thought about it or why that was the best approach for this particular customer, how their mind was able to process the information and think of solution that was never stated in their manuals. Evidence of this is provided in subsequent sections. Let us start by imagining an example of this form of tacit knowing that we know but we cannot tell. A first-time car learner would always have problem coordinating and driving a car in a straight line if they were to take both hands off the wheels. However, with an expert car driver, they can take both hands off the steering and still be able to maintain a decent straight line while driving. You may tell the learner to sit in a particular position, press or ease off the gas pedal in a certain way, amongst other tips you would give them. However, you try, you simply cannot explain a type of skill that has been gained overtime and by 
becoming an expert through practice. The learner on the other hand, despite following all instructions with details would still be unable to drive in a coordinated way without their hands on the wheel because they do not possess the knowledge, neither do they understand the dynamics of what the expert is trying to relay except they practice over time.

Polanyi (1962) distinguishes between two types of knowing, one in which you know a thing by "attending to it" and the other in which we know a thing by "relying on our awareness" of it. He refers to the latter way of knowing as tacit knowledge and argues that both types of knowledge are distinct and are mutually exclusive. He adds that those things we know by attending to them the way we attend to an entity are things we can tell and explain. And those things we know by relying on our awareness are things that we are not certain of and mostly ignorant about. This may explain why little research has been done on the understanding and the application of tacit knowledge. People are not very aware of it and thereby cannot fully explain it.

In call center organizations, the agents are often able to detect tone of voice or the mood of the speaker and tell if they are either happy or upset. They are able to respond appropriately to each unique case after taking note of these emotions. Polanyi describes this as "physiognomy", which is an intellectual skill. He considers these instances of knowing the characteristics of a disease, specimen of species, mood in a face or identity of a person. He regards this ability to recognize a physiognomy a form of tacit knowing which looks like that of a skill. This may explain how agents are able to distinguish these complex patterns in their callers without being able to tell the mechanics of how they discriminate between these features. Call center agents become experts through practice from acquiring explicit knowledge and application of practicing it tacitly over a period. Polanyi gives an example of a medical practitioner who learns of several symptoms of 
disease from textbooks, but that knowledge only becomes useful when the student learns to apply it. This knowledge is acquired through practice that could not be learnt from books.

Knowledge helps us understand how novices are turned into experts through communities, how context helps in problem solving and how working across boundaries can be challenging because knowledge in embedded in local practices (Cook \& Yanow, 1993). In Orr's study (1996), knowledge was viewed as a conversation and social practice after observing technicians who worked on repairing photocopiers used storytelling rather than manuals or formal training. Tsoukas \& Vladimirou (2001) study of call center agents show how they share their experiences informally on the job and also when they go out for break. This shows the importance of how knowledge is created through communication processes. As Brown and Duguid argues, operators develop diagnostic skills through their experiences and their involvement in community of practice, which over time becomes tacit to them.

\section{Tacitness in practice}

Davenport and Prusak (1998) argue that those who have knowledge see patterns and these patterns are more evident to experienced workers who respond efficiently and appropriately to task. This is different from novice workers who build answers to questions every time. Expert workers are skilled at navigating and dealing with complexities of problems in the workplace unlike the novice worker who may be confused. They refer to scripts as internalized responses that provides us alternatives through a maze which saves us the trouble of consciously selecting steps along the way. These scripts are played so quickly that we may not be aware of them until it becomes second nature to us. We provide answers to questions or arrive at solutions automatically, that it becomes so intuitive we do not understand how we got there. Brown and Duguid (1991) argue that through engagement in a community of practice, operators develop skills over time that 
becomes tacit. They discuss how operators are deprived of multiple cues that would have been derived from a face-to-face communication. When operators were asked how they handled certain problems and in what ways, they were unable to put it into words (Tsoukas and Vladmirou, 2001).

Brown and Duguid (1991) give an example of how an operator is able to discern when a customer is unhappy, angry, confused etc not only by their words but through their tone of voice. Experienced operators can decipher these minutia details in customer behaviors quickly and efficiently. It shows a vital component of organizations that provide services virtually and how operators need to have perceptual skills to understand what goes on at the other end (Tsoukas and Vladimirou, 2001). This leads to the question of how expert operators are able to teach novice workers how to decipher these cues, how and when to apply certain behaviors in response to each scenario, how to intuitively know which scenario works best and for which type of client? In understanding the dynamics and role that tacit knowledge plays, organizations across different expertise may be able to efficiently train novice employees in the utilization and application of tacit knowledge.

\section{Shared Language and Collaboration}

In call center organizations, there are rules that have been created whereby these workers have to give standardized responses to standardized inquiries, where they are trained to identify typical problems and give appropriate solutions (Tsoukas and Vladimirou, 2001). They add that an organizational task is achieved when individuals have a shared sense of what rules mean during the course of their work. In most scenarios in this job roles, these callers may have to break away from the norms and protocols of the organization. This leads me to ask what happens when the context of the call does not fall into the standardized responses and queries? How do these 
knowledge workers respond in these situations? Do they apply some form of tacit knowledge in the course of their work?

Kuhn and Jackson (2008) studied a problem-solving exchange between a call center representative and a caller. The interaction between the two parties was straightforward, quick, and without argument because the caller had some level of knowledge of the issue and was able to relay that to the rep. Both parties were able to establish a common language which made the interaction seamless. For knowledge transfer to take place, both parties in a call interaction would have to establish a common knowledge for the problem to be identified and solved. Kuhn and Jackson add that both parties must show that they have enough similar understandings of each other's roles and share interactional scripts and a common code. They add that an operator's ability on knowing how to act depends on contextual and technical knowledge as well as hoping others in the situation can share understanding of that knowledge. For instance, a caller asking for a certain information is being kept on hold while the operator can ask a fellow colleague for more information or clarification. These situations often involve situational factors and implicit understandings.

An important part of an operator's job is the communal nature of the job, mostly in an open office space, which always leads to collaboration between workers. Individual learning is deeply embedded in group learning in certain job functions (Brown and Duguid, 1991). Operators often work individually, yet they also have to ask clarifying questions from the rest of the group when faced with a hard situation. Organizations gather, store and retrieve information in different ways. For instance, in organizations that have customer care department, they respond to customer queries by pulling up information electronically or in printed form (Tsoukas \& Vladimirou, 2001). This electronic information can be in the form of computerized databases that helps these operators 
easily identify the specific information needed to respond to the customer query. Or it may help perform specific tasks for the customer virtually such as setting up an account. These databases may also serve as a platform for pulling up directories inquiries or transferring the customer to the appropriate units such as in 911 calls. They add that sometimes operators pull information in the printed form through manuals that contains information of several issues. These customer care representatives are usually in a position where they have knowledge embedded in different forms like being stored in printed and electronic forms, available for retrieval at their disposal, that enables them respond to customer queries.

In this type of organizations, speed and accuracy is vital in keeping the customer satisfied. The operator is required to have knowledge of using information systems in identifying and navigating the databases to pull up the appropriate information. Using these information systems goes beyond just accessing important information but also developing memory system that is garnered from experiences of the operator and the shared stories of other operators in their community (Tsoukas \& Vladimirou, 2001). This highlights the importance of shared experiences amongst expert operators but does not consider how new operators are able to navigate this job role and how these experiences are explicitly stated or implied to them. In their shared work-related examples to one another, are there situations where new operators are unable to grasp the information being passed or the context of it due to their lack of experience? How are these new operators able to understand this tacit form of knowledge from their shared community and apply it on the job?

Operators are faced with crossing knowledge barriers in their job roles. For instance, customers would typically not be able to articulate their queries explicitly, and the operators would have to ask clarifying questions, infer the issue, and proffer a possible solution. These workers are 
faced with engaging with customers across boundaries and sorting through ambiguities of these calls while streamlining how to solve the issues. Contextual information is usually provided by customers and sometimes problems that seem simple need the diagnostic skills of the operators (Tsoukas and Vladimirou, 2001).

\section{Storytelling}

In recent years, studies have shown renewed interest in the role storytelling play in organizations (Gabriel, 2000; Sole \& Wilson, 2002; Esobi, 2020; Brown, Prusak, Denning, Groh, 2005; Boje, 2008; Barker \& Gower, 2010). This realization that knowledge cannot be solely be completely codified and categorized into different forms may be one of the reasons for this new interest (Sole \& Wilson, 2002). They add that stories are a communicative form and organizations are seeking these forms. They share how Johnson \& Johnson is making a collection of employee stories in an online database and described this approach as a form of absorbing knowledge through gathering stories. Other scholars have also looked at how story telling helps in problem solving, in rebranding organization, in socializing new employees, learning, sense making etc (Mitroff \& Kilmann, 1975; McWhinney \& Battista, 1988; Louis, 1980; Brown, 1982; Boje, 2008; Abimbade, 2019; Helmer, 1989) and most especially to share tacit knowledge (Orr, 1996; Lasode, 2020).

In Orr's (1996) ethnographic study on experienced technicians working on photocopiers showed the triadic relationship between technician, customer and the machine. The study revealed one main form of the practice in the organization was narration whereby diagnosing the state of the machine involved creating a detailed account of the issue. In the process of giving narration, diagnosis are preserved in these accounts to their fellow technicians which helps in community interaction and social distribution. Orr states how the main means the technicians stay very informed of the constant development of the machines activities was through telling narratives. 
Orr adds that once these stories have been told, they become artifacts that are distributed and preserved and through which experiences are reproduced and reused. In addition, these stories are also ways in which ones' competence and skill is revealed and to show that one is part of the community. With the spread of these stories, members in such organizations are able to identify quickly another colleague who would be skilled in solving a particular problem.

\section{Barriers in Communication Practice}

Communication practices in call center organizations can be a bit difficult and it takes practice to be able to engage efficiently with the constant flow of customer queries. In everyday exchanges, interruptions occur that could either disrupt the communication flow or add to the information being transmitted between both parties. These operators deal with customers from different ethnicity having varying accent. Sometimes understanding the caller from the other end can be difficult especially if the customer is angry, speaking fast and wants to get his issue resolved immediately. The operator engages in calming the client, understanding the questions being asked while also navigating either the electronic or physical databases in a timely manner but also most importantly, intuitively responding to that customer in the spur of the moment. Tracy \& Tracy (1998) in their study on the rudeness at 911 explains the attacks that call takers face when dealing with callers. They argued with them, cursed them, showed disrespect or contempt and often implied that operators were incompetent and unreasonable. These workers have to maintain a sense of professionalism and politeness. Despite standardized strategies and protocols available for operators to follow accordingly, sometimes they have to apply knowledge as the context fits.

Improvisation enables the application of tacit knowledge in these organizations. There are scenarios whereby resources to solve a particular problem is unavailable or unknown and operators must improvise. Cases where technology does not function as scripted solution was supposed to 
work, and the operator has to apply his/her own knowledge (Kuhn \& Jackson, 2008). A situation where a novice operator has been engaged with a customer for an unusually long time, other operators would be able to sense when to give their input or help in giving information to solve the issue. The operators can engage in a collaborative form of diagnosing the problem and proffering solution in the background. There are some organizations whose main function is in the manufacturing of mechanical and chemical substances, in which the employees deal with assessing and managing risks daily (Maguire \& Hardy, 2013). It is important for these employees to fully understand and assess the risk involved as this is vital to the safety of the employees (Hass \& Mattson, 2016). Same applies to call center agents, where understanding and assessment of the customers' problem is vital as that would determine how they satisfy the clients. Therefore research shows that constructed safety messages and proper training would aid workers in responding to risks (Brahm \& Singer, 2013). Proper training in the art of making employees situationally aware and going beyond just following constructed messages will help employees respond to unforeseen circumstances.

Through improvisation, call center operators can meet the demands of their jobs and able to personalize how they manage customers issues beyond the formal corporate manuals and information of the organization. For instance, operators made notes from their trainings or points they scribbled down from answers to customers queries they encountered in the past which they were unable to locate through formal systems (Brown \& Duguid, 1999). These notes are unique to their them and their experiences and are better and easier references than weaving through the databases of the organizations formal systems. Operators can weave through this data and transform information to knowledge by enacting the abstract information of "if, then" statements 
in the rule books. Nonetheless, they must adapt and take the context of their conversation with a caller into consideration before then applying the rules to the circumstances at hand.

Call center representatives undergo many months of training learning the world from the perspective of the institution and understanding how to offer help in ways the institution usually delivers its services (Tracy \& Tracy, 1998). In Orr's study, he was able to show that reps had to make sense of their work with machines beyond what the managers expected or allowed from the trainings and manuals. In other words, they developed a deeper understanding of the machines, not through the trainings but through the rigorous routine of their daily work (Brown \& Duguid, 1991). In the practice of telling stories, these workers can discuss hunches, misconceptions, scenarios etc. They can keep track of decisions that worked in certain scenarios and possible solutions to apply in another scenario. Manuals, databases, and trainings may inform them on what to do but not why, and reps stories keep a causal account of the machines in cases where documentation fails (Brown \& Duguid, 1991). These stories are vital in circulating work practices faster than databases of information. Organizations that do not promote or frown upon interactions formally during work periods may be missing out on a key component in inducting their members the work process. They suggest that these processes will help workers bridge the gap between what the organization supplies and what is needed in a certain community. They consider stories acting as a repository of gathered wisdom. I argue that within these stories shared between reps lies a form of knowledge, so embedded that the novice operator must discern the underlying messages being passed between the expert operators. This tacit knowledge is embedded in the practice of these operators, but also in the stories which they share. 


\section{Discussion and Conclusion}

Managing organizational knowledge goes beyond just managing hard bits of information but maintaining and strengthening social practices (Kreiner, 1999). Organizations go through changes more rapidly with workers entering and leaving the organization, new policies and requirements are implemented, and the tools available to perform their job changes (Barley \& Treem, 2020). Operators tend to improvise in their practice to satisfy the demands of their task in a more efficient and effective way (Orlikowski, 1996). Ford \& Stephens (2018) suggests that instead of organizations to focus on just training workers in identifying and responding to risk, there should be an understanding of how communicative interactions affects their perceptions of risks. This can also be applied to call center organizations where employees can be trained beyond the art of just identifying and responding to problems.

Brown \& Duguid (1991) suggest organizations create a conceptual matrix which contains generic categories (e.g 'happy customer', 'efficient service' etc) and their interrelations (e.g high quality service makes customers happy') for their members to follow. This would enable organization members to search and locate appropriate responses in dealing with different customers. This would be one way for novice operators to get assimilated into the working knowledge of the organization in a seamless manner. They argue that for organizational knowledge to be managed, these practices that are unreflective need to be turned into a reflective one. They go further to explain that an unreflective practice is one in which we act, do things effortlessly by watching rules of our practice but unable to state what they are. In this sense, we are all unreflective practitioners. Mastery of a practice in an unreflective way is not enough. They suggest that for us to teach new members to be efficient and effective members of the practice, we need to reflect on things that improve our practice, articulate those things and make them explicit. However, Brown 
and Duguid (1991) do admit that a less observed form of knowledge is the heuristic knowledge which is developed while employees are engaged in their job. This type of knowledge depends on workers social relations, perceptual skills, motivations etc and it cannot be managed in the way formal information is codified.

In Orr's study, we can see that the standard available information made for the technicians were often unreliable and most time unclear. The stories shared had a sense of credibility in them as these were personal accounts from known experienced individuals which could be added along with information from manuals. These stories also provided a framework for novice operators and make the claims valid since the solutions to the issues has been previously tested with an expected outcome. In organizations, stories from colleague also reveal tacit fear and deep assumptions of employees, their attitudes, and feelings about the workplace (Argyris, 1978; Sole \& Wilson, 2002). While employees should sharpen their listening skills by learning to listen below the surface, employers should also try to keep track of stories and gauge if it creates a positive or negative image of the organization. As this may also determine the length novice employees stay with the organization.

\section{References}

Abimbade, O., Adedoja, G., Fakayode, B., \& Bello, L. (2019). Impact of mobile-based mentoring, socio-economic background and religion on girls' attitude and belief towards antisocial behaviour (ASB). British Journal of Educational Technology, 50(2), 638-654.

Abimbade, O., Akinyemi, A., Bello, L., \& Mohammed, H. (2017). Comparative Effects of an Individualized Computer-Based Instruction and a Modified Conventional Strategy on Students' Academic Achievement in Organic Chemistry. Journal of Positive Psychology and Counseling, 1(2), 1-19.

Adedoja, G., \& Oluwadara, A. (2016). Influence of Age and Training on Planning Instruction Using Mobiles Phones by Pre-service Social Studies Teachers. Science and Education, $3(1), 1-6$. 
Adedoja, G., Abimbade, O., Akinyemi, A., and Bello, L. (2017). Discovering the Power of Mentoring using Online Collaborative Technologies. In C.O.O Kolawole, R.O. Akinbote, T.A. Ige, G. Adedoja, and A. Aremu (Eds.). Advancing Education through Technology. Ibadan His Lineage Publishing House. Pp. 261 - 281.

Barker, R. T., \& Gower, K. (2010). Strategic application of storytelling in organizations: Toward effective communication in a diverse world. The Journal of Business Communication (1973), 47(3), 295-312.

Barley, W. C., Treem, J. W., \& Leonardi, P. M. (2020). Experts at coordination: Examining the performance, production, and value of process expertise. Journal of Communication, 70(1), 60-89.

Boje, D. M. (2008). Storytelling organizations. Sage.

Brown, M. H. (1982) That Reminds Me of a Story: Speech Action on Organizational Socialization. Unpublished PhD Thesis, University of Texas at Austin (cited in Boyce, 1996)

Brown, J. S., \& Duguid, P. (1991). Organizational learning and communities-of-practice:

Toward a unified view of working, learning, and innovation. Organization science, 2(1), 40-57.

Brown, J. S., Prusak, L., Denning, S., \& Groh, K. (2005). Storytelling in organizations: Why storytelling is transforming 21 st century organizations and management. Routledge.

Cook, S. D. N., \& Yanow, D. (1993). Culture and organizational learning. Journal of Management Inquiry, 2, 373-390.

Davenport, T. H., \& Prusak, L. (1998). Working knowledge: How organizations manage what they know. Harvard Business Press.

Esobi, I. C., Lasode, M. K., Anyanwu, C. I., Barriguete, M. F., Okorie, M. A., \& Lasode, D. O. (2021). Food Insecurity, Social Vulnerability, and the Impact of COVID-19 on Population Dependent on Public Assistance/SNAP: A Case Study of South Carolina, USA. Journal of Food Security, 9(1), 8-18.

Esobi, I. C., Lasode, M. K., Anyanwu, C. I., Degbe, E., Barriguete, M. F., Okorie, M. A., ... \& Okegbe, S. (2020). Nutritional Impact of COVID-19 and Its Implications on Atherosclerosis. World, 8(1), 16-21.

Esobi, I. C., Lasode, M. K., \& Barriguete, M. F. (2020). The Impact of COVID-19 on Healthy Eating Habits. J Clin Nutr Heal, 1(1), 001-002. 
Ford, J. L., \& Stephens, K. K. (2018). Pairing Organizational and Individual Factors to Improve Employees’ Risk Responsiveness. Management Communication Quarterly, 32(4), 504533. https://doi.org/10.1177/0893318918774418

Gabriel, Y. (2000). Storytelling in organizations: Facts, fictions, and fantasies: Facts, fictions, and fantasies. OUP Oxford.

Haas, E. J., \& Mattson, M. (2016). A qualitative comparison of susceptibility and behavior in recreational and occupational risk environments: Implications for promoting health and safety. Journal of Health Communication, 21, 705-713. doi:10.1080/10810730.2016.1153765

Helmer, J. E. (1989). Between horses: An ethnographic study of communication and organizational culture at a harness track. Unpublished dissertation. University of Illinois at Urbana-Champaign.

Kuhn, T., \& Jackson, M. H. (2008). Accomplishing knowledge: A framework for investigating knowing in organizations. Management Communication Quarterly, 21(4), 454-485.

Kreiner, K. (1999). Knowledge and mind: The management of intellectual resources. In Advances in Managerial cognition and organizational information processing (pp. 129). JAI Press.

Lasode, M., Esobi, I., Anyanwu, C., \& Lasode, D. (2020). Assessing Urban Land use Change in New Braunfels, Texas from 2013 to 2020.

Louis, M. R. (1980). "Surprise and sense-making: What newcomers experience when entering unfamiliar organizational settings.” Administrative Science Quarterly, 23, 225-251.

Maguire, S., \& Hardy, C. (2013). Organizing processes and the construction of risk: A discursive approach. Academy of Management Journal, 56, 231-255.doi:10.5465/amj.2010.0714

McWhinney, W., Battista, J. (1988). "How remythologizing can revitalize organizations." Organizational Dynamics, August: 46-58

Mitroff, I., Kilmann, R. H. (1975). "Stories Managers Tell: A New Tool for Organizational Problem Solving." Management Review, July, 18-28

Oluwadara, A., Kolapo, B. L., \& Esobi, I. C. (2020). Designing a Framework for Training Teachers on Mobile Learning in Sub-Sahara Africa.

Oluwaseun, O., Tolulope, F., Lukuman, B., \& Ikechukwu, E. C. (2020). Improving Pre-service Teachers' Memory and Retention Using Durable Memory Strategies in an Instructional Technology Course. American Journal of Educational Research, 8(11), 847-855.

Orlikowski, W. J. (1996). Improvising organizational transformation over time: A situated change perspective. Information systems research, 7(1), 63-92. 
Orr, J. E. (1996). Talking about machines: An ethnography of a modern job. Ithaca, NY: ILR Press

Polanyi, M. (1962). Tacit knowing: Its bearing on some problems of philosophy. Reviews of modern physics, 34(4), 601.

Sole, D., \& Wilson, D. G. (2002). Storytelling in organizations: The power and traps of using stories to share knowledge in organizations. LILA, Harvard, Graduate School of Education, 1-12.

Tracy, K. and S. J. Tracy (1998). "Rudeness at 911 Reconceptualizing Face and Face Attack." Human Communication Research 25(2): 225-251.

Tsoukas, H., \& Vladimirou, E. (2001). What is organizational knowledge? Journal of management studies, 38(7), 973-993. 